\title{
Early systolic closure of the aortic valve
}

\author{
P WONG, L COTTER, D G GIBSON \\ From the Department of Cardiology, Brompton Hospital, Fulham Road, London
}

SUMMARY Six patients with early systolic closure of the aortic valve are described with mitral regurgitation, double outlet right ventricle, left ventricular diverticulum, congestive cardiomyopathy, Eisenmenger ventricular septal defect, and aortic regurgitation with an aneurysmal ascending aorta, respectively. None had evidence of subaortic stenosis.

Early systolic closure of the aortic valve is thus not diagnostic of subvalvular aortic stenosis but is a non-specific finding.

Early or mid-systolic closure of the aortic valve has been described as being of great diagnostic value in the diagnosis of subvalvular aortic stenosis ${ }^{1-3}$ whether caused by fixed subaortic stenosis or by hypertrophic obstructive cardiomyopathy. Value has been placed on the presence and even the extent and timing of early systolic closure of the aortic valve in estimating the severity of the outflow tract gradient in subaortic stenosis and the presence of intraventricular gradients in hypertrophic obstructive cardiomyopathy. We present six patients with other heart disorders, with varying degrees of early systolic closure of the aortic valve, none of whom had any evidence of subvalvular aortic stenosis.

\section{Case reports}

\section{CASE 1}

A 41-year-old woman was entirely asymptomatic until March 1979 when she noted atypical chest pain. Clinically there was no abnormality. Electrocardiogram showed sinus rhythm, normal QRS, and inverted T waves in V3-6, III, and VF. Chest $x$-ray film was normal. Echocardiography (Fig. 1) showed early systolic closure of the aortic valve. At cardiac catheterisation, the left ventricular enddiastolic pressure was normal. There was a left ventricular diverticulum at the apex. There was no cavity obliteration, no gradient was recorded in the left ventricle, and the left ventricular outflow tract was normal haemodynamically and angiographically.

\section{CASE 2}

A 73-year-old woman had been noted to have a heart murmur for 12 years and had been breathless Received for publication 22 January 1980 on exertion for this period. Five months before admission she began to deteriorate and became orthopnoeic. She was admitted in severe pulmonary oedema with clinical evidence of severe mitral regurgitation. Echocardiography showed intermittent (Fig. 2a and 2b) early systolic closure of the aortic valve and a flail posterior cusp of the mitral valve prolapsing into the left atrium. At operation (Mr M Paneth) the presence of ruptured chordae of the posterior cusp of the mitral valve was confirmed.

\section{CASE 3}

A 12-year-old boy presented with a history of limiting exertional dyspnoea. The abnormal cardiovascular physical findings were confined to ausculta-

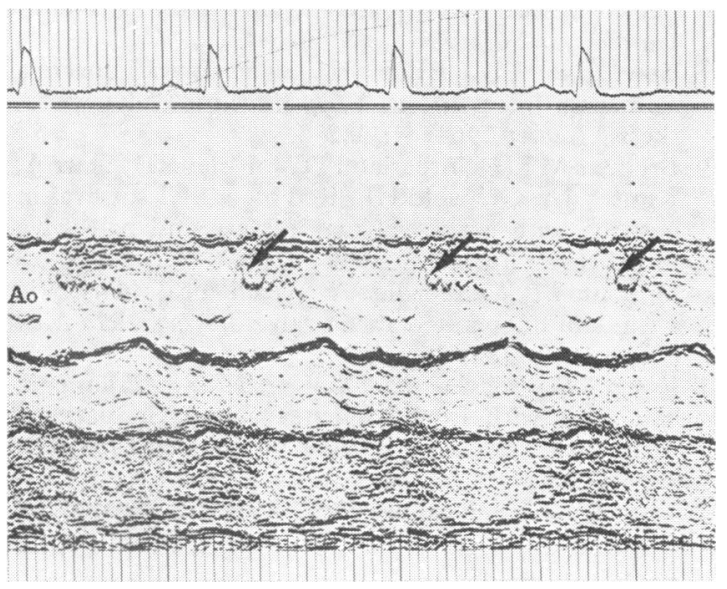

Fig. 1 Early systolic closure of the aortic valve in a patient with a diverticulum of the left ventricle. Ao, aorta. 


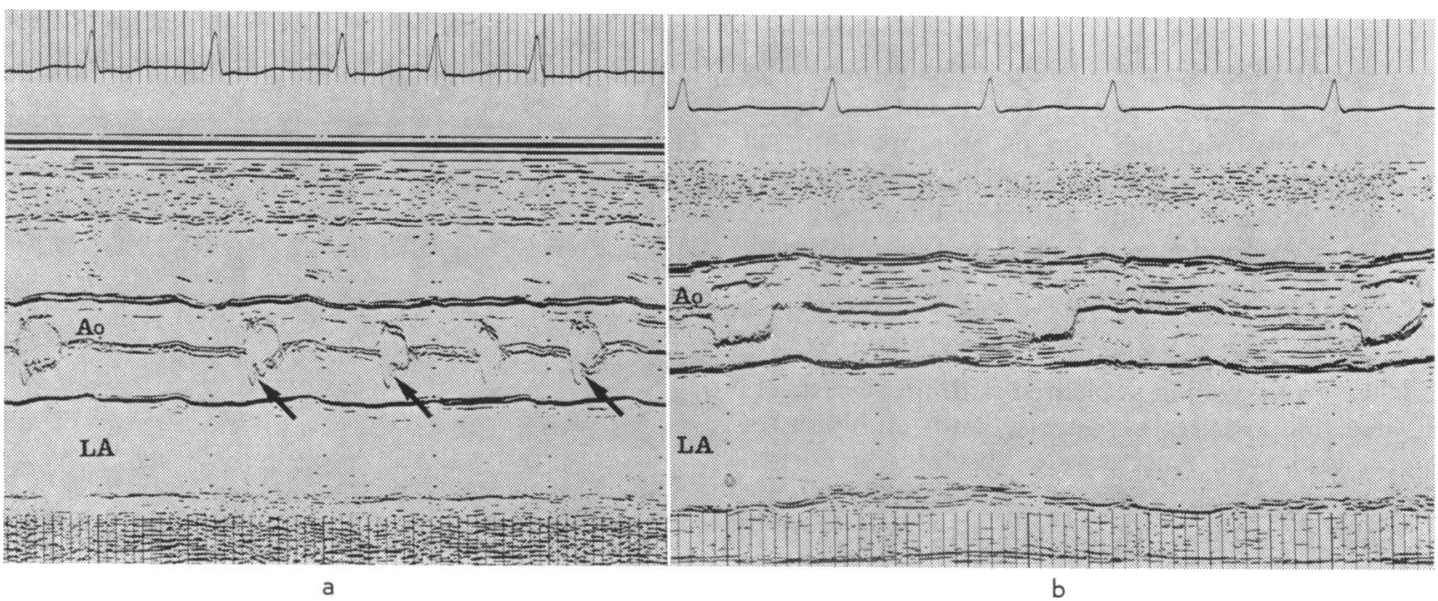

Fig. 2a and $\mathrm{b}$ Intermittent early systolic closure of the aortic valve in a patient with mitral regurgitation due to ruptured chordae. $L A$, left atrium.

tion with a normal first sound, single second sound, and a grade $3 / 6$ harsh systolic murmur with a thrill radiating throughout the praecordium and into the carotids. There were no other abnormal physical findings. The electrocardiogram showed sinus rhythm axis +120 degrees and right ventricular hypertrophy. Chest $x$-ray film was normal.

Echocardiography showed normal left ventricular and mitral valve echoes. A left ventricular to aortic scan showed override of the aorta and the unexpected finding of early systolic closure of the aortic valve (Fig. 3 ).

A clinical diagnosis of Fallot's tetralogy was made though the possibility of subaortic stenosis was raised by the echocardiogram. At cardiac catheterisation the findings were those of acyanotic Fallot's tetralogy with a tight infundibular stenosis and a ventricular septal defect with equal right and left ventricular pressures. There was no evidence of left ventricular outflow tract obstruction. At operation (Mr C Lincoln) the final diagnosis was revised to double outlet right ventricle with infundibular pulmonary stenosis and an infraaortic ventricular septal defect. There was no evidence of subaortic stenosis. Postoperative echocardiography showed early systolic aortic valve closure to persist unchanged.

\section{CASE 4}

A 76-year-old woman presented with a three-year history of progressively disabling breathlessness. On examination her heart rate was 120 /minute in atrial fibrillation, jugular venous pressure raised to $12 \mathrm{~cm}$, BP $140 / 100 \mathrm{mmHg}$. The apex was impalpable. The heart sounds were normal with a grade $2 / 6$ pansystolic murmur at the apex. There was no oedema or hepatomegaly and the lung fields were clear. Electrocardiogram confirmed atrial fibrillation with an uncontrolled rate, high left ventricular voltages with non-specific ST-T wave changes laterally. Chest $x$-ray showed an enlarged heart with Kerley B lines and interstitial pulmonary oedema. Echocardiography showed an enlarged left ventricle with diminished posterior wall systolic excursion and an akinetic septum, an enlarged left atrium $(5 \mathrm{~cm})$, normal mitral valve echoes, and early systolic closure of the aortic valve (Fig. 4).

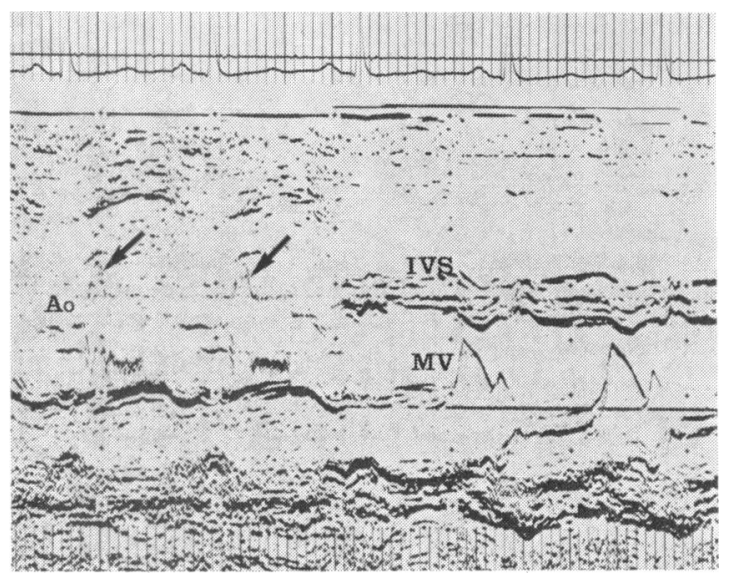

Fig. 3 M-mode sweep from aorta to mitral valve showing early systolic closure of the aortic valve (arrowed). Aortic override of the interventricular septum is also demonstrated. IVS, interventricular septum; $M V$, mitral valve. 
A diagnosis of congestive cardiomyopathy and atrial fibrillation was made and the patient was treated with digitalis and diuretics. On this treatment she improved, her venous pressure returned to normal, her apical systolic murmur disappeared, and her heart size diminished radiographically. Further investigation was considered inappropriate and she was discharged.

\section{CASE 5}

A 44-year-old woman presented with breathlessness on exertion, central cyanosis, and clubbing of fingers and toes. Auscultation disclosed a normal first heart sound, a single second heart sound without murmurs. Blood pressure was 120/70 $\mathrm{mmHg}$. There were no other abnormal findings. She was diagnosed to be suffering from ventricular septal defect with Eisenmenger syndrome and this was confirmed at cardiac catheterisation. Echocardiography showed early systolic closure of the aortic valve (Fig. 5 ).

\section{CASE 6}

A 72-year-old retired accountant presented with a seven months' history of dyspnoea. On examination the pulse was $70 /$ minute, regular, water hammer in character, venous pressure normal. The first heart sound was normal, the second single. There was a grade $3 / 6$ ejection type systolic murmur best heard at the base, radiating into the neck, and a grade 4/6 long early diastolic murmur best heard at the right sternal edge. There was no oedema or hepatomegaly and the lungs were clinically clear. Electrocardiogram showed sinus rhythm and left ventricular hypertrophy "with strain pattern". Chest $x$-ray

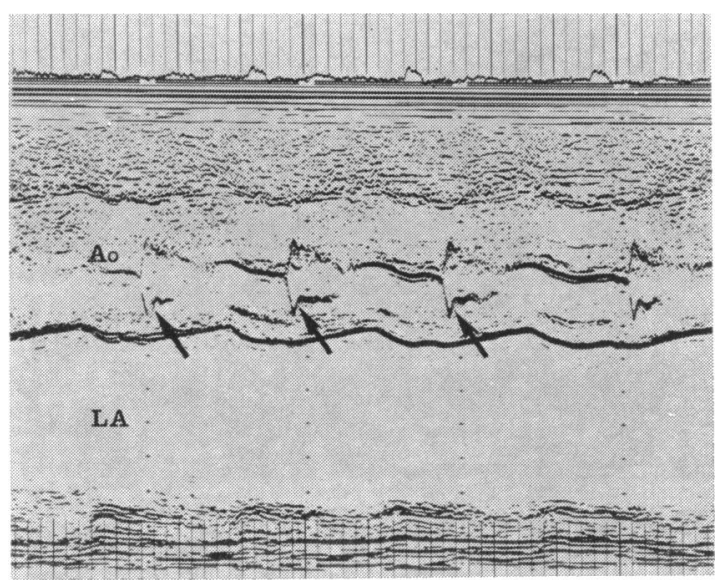

Fig. 4 Early systolic closure of the aortic valve in a patient with congestive cardiomyopathy.

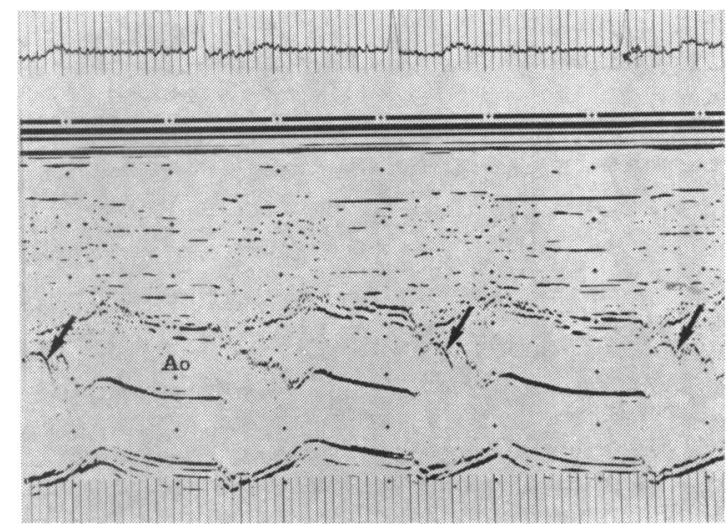

Fig. 5 Early systolic closure of the aortic valve in a patient with ventricular septal defect complicated by the Eisenmenger reaction.

showed cardiomegaly with unfolding of the aorta and an aneurysm of the ascending aorta. Echocardiography of the aortic valve showed distinct early systolic closure (Fig. 6). Aortography disclosed a greatly dilated ascending aorta, aneurysmal from the aortic valve ring to the origin of the innominate artery accompanied by severe aortic regurgitation. At surgery (Mr M Paneth) the aortic valve consisted of three flimsy leaflets in a dilated ring and there was an aneurysm of the ascending aorta. There was no evidence of subvalvar outflow tract obstruction. After aortic valve replacement and resection of the aneurysm the patient made an uneventful recovery.

\section{Discussion}

Early systolic closure of the aortic valve has long been thought to be highly suggestive of either discrete subaortic stenosis or hypertrophic obstructive cardiomyopathy, systolic closure of the aortic valve being said to occur earlier in the former and later in the latter. Davis et al. ${ }^{1}$ suggested that the echocardiographic findings of "aortic valve closure early in systole, persistent valve closure throughout the remainder of systole, coarse fluttering of the leaflets, and absence of asymmetric septal hypertrophy" are suggestive if not specific for discrete subaortic stenosis, while Silove et al. ${ }^{4}$ found $\mathrm{M}$-mode echocardiography to be diagnostic in nine out of 10 patients with discrete subaortic stenosis. All nine patients reported by Krajcer et $a .^{2}$ with discrete subaortic stenosis had early systolic closure, and five out of six retained this feature after operation for relief of left ventricular 
outflow tract obstruction. Nineteen of 20 patients with discrete subaortic stenosis reported by Kreuger et $a l .{ }^{3}$ had this feature, and they maintained that "the echo features of very early partial closure and valve flutter, and narrow left ventricular outflow tract, are clear enough and specific enough to be used in assessing patients with clinical signs of left ventricular outflow tract obstruction". The occurrence of early systolic closure in hypertrophic subaortic cardiomyopathy is also well recognised. It has been said to correlate well with resting intraventricular pressure gradients, and thought to be a more specific predictor of outflow obstruction than asymmetric septal hypertrophy and systolic anterior movement of the mitral valve. ${ }^{56}$ However, our cases clearly show that early systclic closure in fact can occur in its various forms in conditions other than subvalvular left ventricular outflow tract obstruction. Cases 1, 3, 5, and 6 were confirmed by cardiac catheterisation and angiography, and cases 2, 3, and 6 at operation. Case 4 had no clinical evidence of either discrete subaortic stenosis or hypertrophic obstructive cardiomyopathy. Early systolic closure of the aortic valve is thus a nonspecific finding in a variety of disorders. Though it can occur in patients with hypertrophic obstructive cardiomyopathy, or discrete subvalvar aortic stenosis, or indeed the tunnel form of subaortic stenosis, ${ }^{7}$ it may also be seen in congestive cardiomyopathy, mitral regurgitation, ventricular septal

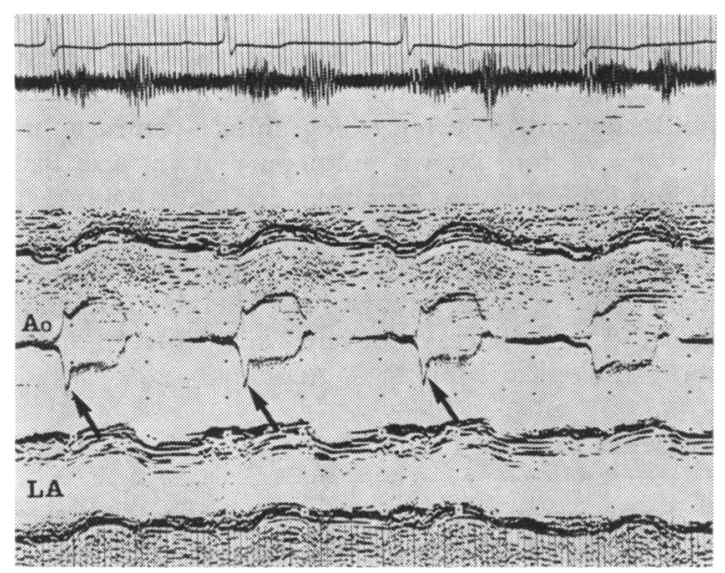

Fig. 6 Early systolic closure of the aortic valve in a patient with aortic regurgitation and an aneurysmal ascending aorta. defect, ${ }^{8}$ rupture of right sinus of Valsalva aneurysms, ${ }^{9}$ diverticulum of the left ventricle, dissection of the aorta, ${ }^{10}$ aortic regurgitation with a dilated ascending aorta, and double outlet right ventricle. Its genesis in these conditions can be speculated upon but is unknown.

Although the occurrence of early systolic closure of the aortic valve in the presence of signs of left ventricular outflow tract obstruction may suggest a form of subvalvular stenosis, its diagnostic significance should not be overemphasised.

\section{References}

1 Davis RJH, Feigenbaum H, Chang S, Konecke L, Dillon J. Echocardiographic manifestations of discrete subaortic stenosis. Am f Cardiol 1974; 33: 277-80.

2 Krajcer Z, Orzan F, Pechacek LW, Garcia E, Leachman RD. Early systolic closure of the aortic valve in patients with hypertrophic subaortic stenosis and discrete subaortic stenosis. Am $\mathcal{F}$ Cardiol 1978; 41: 823-9.

3 Kreuger SK, French JW, Forker AD, Caudill CC, Popp RL. Echocardiography in discrete subaortic stenosis. Circulation 1979; 59: 506-13.

4 Silove ED, Rigby ML, Singh SP. Value of echocardiography in distinguishing valvar from subvalvar aortic stenosis. In: Proceedings of the British Cardiac Society and Swedish Society of Cardiology (abstract). Br Heart $\mathcal{F}$ 1978; 40: 443.

5 Feizi Ö, Emanuel R. Echocardiographic spectrum of hypertrophic cardiomyopathy. Br Heart $\mathcal{f} 1975 ; 37$ : 1286-302.

6 Chahine RA, Raizner AE, Nelson J, Winters WL Jr, Miller RR, Luchi RJ. Mid systolic closure of aortic valve in hypertrophic cardiomyopathy. $\mathrm{Am} \mathcal{F} \mathrm{Cardiol}$ 1979; 43: 17-23.

7 Ten Cate FJ, Van Dorp WF, Hugenholtz PG, Roelandt J. Fixed subaortic stenosis. Value of echocardiography for diagnosis and differentiation between various types. $B r$ Heart $\mathcal{F} 1979$; 41 : 159-66.

8 Feigenbaum H. Echocardiography. 2nd ed. Philadelphia: Lea \& Febiger, 1976: 159-61.

9 Johnson ML, Warren SG, Waugh RA, Kisslow JA, Sabiston DC, Lester RG. Echocardiography of the aortic valve in non-rheumatic left ventricular outflow tract lesions. Radiology 1974; 112: 677-84.

10 Candell-Riera J, del Castillo HG, Rius J. Aortic root dissection. Another cause of early systolic closure of the aortic valve. $B r$ Heart $f 1980 ; 43$ : 579-81.

Requests for reprints to Dr D G Gibson, Cardiac Department, Brompton Hospital, Fulham Road, London SW3 $6 \mathrm{HP}$. 